\title{
Erratum
}

\section{Erratum: Speed et al., Apparent Genetic Rescue of Adult Shank3 Exon 21 Insertion Mutation Mice Tempered by Appropriate Control Experiments}

In the article "Apparent Genetic Rescue of Adult Shank3 Exon 21 Insertion Mutation Mice Tempered by Appropriate Control Experiments," by Haley E. Speed, Mehreen Kouser, Zhong Xuan, Shunan Liu, Anne Duong, and Craig M. Powell, which was published online on August 26, 2019, contains a factual error in the Discussion section. The authors mistakenly noted in three paragraphs that the CAGGCre-ER ${ }^{T M}$ transgenic mouse line used in the study was the same as that used in the study by Mei et al. (2016) and published in Nature (https://doi.org/10.1038/nature16971). The authors are now aware that Mei et al. (2016) used an independently generated version of the CAGGCre-ER ${ }^{T M}$ transgenic mouse line. Mei et al. (2016) used the transgenic line created by Guo et al. (2002) and published in Genesis (https://doi.org/10.1002/gene.10021). The authors' transgenic line was created by Hayashi and McMahon (2002) and was published in Developmental Biology (https://doi.org/10.1006/ dbio.2002.0597). This correction does not affect the conclusions of the article.

https://doi.org/10.1523/ENEURO.0465-19.2019 